\title{
GILBERTO FREYRE E O HORIZONTE DO MODERNISMO
}

\author{
Mariza Veloso
}

Resumo. O artigo discute a inserção de Gilberto Freyre no horizonte do modernismo brasileiro e constrói seu argumento a partir dos ideais que o intelectual compartilha com sua geração. As principais linhas de interpretação responsáveis pela renovação do pensamento brasileiro podem ser sumarizadas pela substituição do conceito de Raça pelo de Cultura e pela alteração que provoca nos conceitos de História, Memória, Tempo e Tradição.

Palavras-chave: cultura brasileira, raça, história, tradição.

\section{Introdução}

Já plenamente inserida no horizonte modernista, uma das principais obras de Gilberto Freyre - Casa-Grande e Senzala - foi publicada no ano de 1933. Em seu primeiro prefácio, manifestando o sentido de vanguarda por intermédio da idéia de missão, o autor expressa a urgência em promover uma interpretação renovada da cultura brasileira:

O professor Franz Boas é a figura de mestre de que me ficou até hoje maior impressão. Conheci-o nos meus primeiros dias em Colúmbia. Creio que nenhum estudante russo, dos românticos, do Século XIX, preocupou-se mais intensamente pelos destinos da Rússia do que eu pelos do Brasil na fase em que conheci Boas. Era como se tudo dependesse de mim e dos de minha

Mariza Veloso é professora do Departamento de Sociologia da Universidade de Brasília e do Instituto Rio Branco - M.R.E. 
geração; da nova maneira de resolver questões seculares. E dos problemas brasileiros nenhum que me inquietasse tanto como o da miscigenação.

Distinguir os traços modernistas na obra de Gilberto Freyre não é tarefa difícil, mas sim complexa. Mesmo diante da singularidade desse autor e ator, e das peculiaridades de sua trajetória intelectual e política no cenário cultural barsileiro, ao que ainda se pode agregar a grande independência de pensamento e atitude que o caracterizam, é possível identificar "afinidades eletivas" entre suas propostas de interpretação da cultura brasileira e algumas proposições fundantes do modernismo, elaboradas por outros intelectuais da mesma geração de autor, Sérgio Buarque de Holanda, Mário de Andrade, Manuel Bandeira.

Em verdade, o modernismo brasileiro, a par de suas múltiplas expressões estéticas, manifestos, publicações e variados subgrupos que o caracterizaram, contém traços comuns de modernidade que abrem novos caminhos analíticos, estéticos e sociopolíticos para o conhecimento da nossa cultura.

Entre esses traços pode-se destacar alguns eixos temáticos definitivos rumo à renovação interpretativa da cultura brasileira, tais como a substituição (pelo menos tentativa) do conceito de raça pelo de cultura e a introdução mais avançada da idéia de meio geográfico, antecipando-se, assim, à própria idéia de meio ambiente, uma vez que voltada mais para uma perspectiva ecológica, em detrimento do então dominante e implacável determinismo geográfico. Mais do que isso, a modernidade operada pelos modernistas incide basicamente na alteração que introduzem nos conceitos de história, tradição, memória e tempo.

Procurar-se-á mostrar no presente artigo como esses traços se inscrevem na obra e na perspectiva analítica de Gilberto Freyre. De igual modo, pretende-se evidenciar como o autor não só inseriuse no movimento modernista, mas também como Gilberto Freyre pode ser considerado legítimo arauto da modernidade no pensamento social brasileiro.

Por fim, procurar-se-á, ainda, evidenciar a atualidade do Mestre de Apipucos para a compreensão da realidade da cultura contemporânea brasileira. 


\section{O personagem Gilberto Freyre}

Seguramente, os anos 20 e 30 descortinaram um dos períodos mais ricos e dinâmicos da história da intelligentsia brasileira. Nesse contexto, emerge entre os intelectuais uma das características mais fecundas do modernismo: a atitude dialógica. Com essa marcante postura, ampliam-se e aprofundam-se as discussões em torno das tradições culturais e das várias tendências que conformaram o Brasil. A dimensão dialógica encontra-se presente tanto entre os intelectuais do período que muito debatem e polemizam, quanto no modo de compreender o Brasil.

Gilberto Freyre, de um lado, possui um grupo de amigos e intelectuais em Recife, Pernambuco, onde em particular se destacam Edson Nery da Fonseca e Ulisses Pernambucano. De outro, relacionase com proximidade com um subgrupo modernista, radicado no Rio de Janeiro, sobressaindo-se Manuel Bandeira, Prudente de Moraes Neto, Rodrigo Melo Franco de Andrade, Sérgio Buarque de Holanda e Afonso Arinos Melo Franco.

Por intermédio de pesquisa de campo sobre a instituição do Patrimônio Histórico e Artístico Nacional ${ }^{1}$, foi possível conhecer a relação de extrema proximidade que Rodrigo M. F. de Andrade (então diretor do SPHAN) e Gilberto Freyre mantiveram ao longo de 30 anos.

Segundo relato de Graciema M. F. de Andrade, mulher de Rodrigo,

Rodrigo passou noites intermináveis lendo e fazendo anotações nos originais de Casa-Grande e Senzala, que Gilberto havia lhe enviado para entregar ao editor Augusto Frederico Schmidt.

Ainda da autora, em pesquisa sobre a obra de Gilberto Freyre, encontra-se outra informação que evidencia a estreita relação entre ambos: na primeira hora de criação do SPHAN (instituição responsável pela preservação do patrimônio histórico e artístico nacional) Freyre fora convidado por Rodrigo para ser o representante daquela Secretaria em Pernambuco. A indicação, contudo, não se concretizou. Nos idos tempos do Estado Novo (1937), o interventor de Pernambuco recusou o nome de Gilberto Freyre por não admitir suas posturas políticas, à época, consideradas "comunistas". 
No entanto, a relação de extrema proximidade entre Gilberto Freyre e o "Patrimônio" (como era chamado) são legítimas e visíveis em inúmeras e concretas situações. Nesse sentido, encontra-se no arquivo pessoal de Rodrigo M. F. de Andrade, hoje sob a guarda da Casa de Rui Barbosa, um rico e significativo conjunto de cartas de Gilberto Freyre a ele endereçadas, onde são brilhantemente discutidas idéias a cerca da "origem" da cultura brasileira, e ainda sobre a tradição cultural e a necessidade de sua preservação.

Há também registros sobre o sistemático relacionamento de Gilberto Freyre com o grupo do "Patrimônio" - um dos mais atuantes subgrupos do modernismo brasileiro -, em função do fato de a Revista do Patrimônio haver publicado no seu número de estréia (1937), trabalho de Gilberto Freyre intitulado Mocambos do Nordeste: algumas notas sobre o tipo de casa mais primitiva do nordeste brasileiro.

Nessa mesma publicação, foram posteriormente publicados inúmeros outros trabalhos de Gilberto Freyre, versando sobre os mais variados assuntos: arquitetura, arte, culinária e organização sociocultural do Brasil.

Sabe-se, também, por intermédio de citações feitas pelo próprio Gilberto Freyre in 'Porque sou e não sou sociólogo' e 'Gilberto Freyre na UnB', de suas relações igualmente próximas com Prudente de Moraes Neto, Sérgio Buarque de Holanda e Lúcio Costa, entre outros membros da "Academia SPHAN".

Mais estreitas, ainda, foram suas relações com Manuel Bandeira: eram amigos-irmãos ou melhor, enfaticamente amigos verdadeiros, onde a "phillia", ou seja, a afinidade espalha-se como fonte em todas as dimensões da convivência. Gilberto Freyre e Manuel Bandeira são amigos que desfrutam o gosto pela experiência brasileira - fundada na miscigenação, na mistura, na ludicidade , no lirismo, nas formas enigmáticas e paradoxais de adaptação das diversas culturas aqui em contato. Em suma, os amigos compartilhavam, em especial, profundo apreço pela tradição.

As afinidades entre os autores são inúmeras. Dignos de registro são o poema Evocação do Recife (1925), de Manuel Bandeira, e o Guia Prático Histórico e Sentimental da Cidade do Recife (1935), onde ambos valorizam a tradição, os rastros do tempo, as formas de sociabilidade e intimidade, revelando, ainda - ao se reportarem à capital 
pernambucana - como uma cidade inteira que se deixa "evocar" pelos sentidos, pelo cheiro, pela cor, pelas relações pessoais.

Em comum com Manuel Bandeira - e este já um traço modernista - é a especial capacidade de Gilberto Freyre apreender a experiência através dos sentidos. Nele, os sentidos parecem recolher, filtrar e fixar a experiência da cidade que, assim percebida, é apresentada como possuidora de um ritmo lento. Nosso "guia" comporta-se como um narrador, relatando a experiência coletiva e a valorização dos sentidos na construção das experiências sociais.

Além dos amigos e interlocutores já mencionados, destacam-se no relacionamento com Freyre também artistas, escritores e intelectuais, como José Lins do Rêgo, Júlio Belo, Cícero Dias e Jorge de Lima e muitos outros modernistas que tiveram o privilégio de compartilhar com personalidade tão inquietante. Freyre sempre nutriu um gosto muito especial pela brasilidade, segundo ele repleta de antagonismos, misturas e mediações simbólicas ricas e inesperadas.

Diálogo também digno de registro foi aquele estabelecido entre Gilberto Freyre e José Lins do Rêgo, onde ambos debatem em profundidade a temática da memória e da volta ao passado. As muitas dimensões da obra de Gilberto Freyre, onde se incluem seus livros, artigos e crônicas para jornais, correspondências com amigos, sua atuação como ator cultural e político e, principalmente, seu papel como intelectual público, têm merecido significativos estudos, o que amplia e complexifica a fortuna crítica do autor.

Num primeiro momento, procurou-se, tão-somente, situar Gilberto Freyre em uma rede social - especialmente aquela formada por "núcleos modernistas". Num segundo momento, pretende-se inserilo em rede discursiva mais ampla, destacando-se as categorias de história, tradição, tempo e memória.

Para homenagear Gilberto Freyre, personagem histórico, contemporâneo de seu próprio tempo, nada mais oportuno do que a aura que acompanha todo começo - como o é este início do ano 2000. E nesse sentido, ninguém melhor para apresentá-lo do que ele próprio. Em seminário comemorativo de seus 80 anos, realizado na Universidade de Brasília, assim se expressou o autor:

No meu caso, nasci, há oitenta anos, brasileiro. Produto, em grande parte, de já antigas raízes brasileiras. De sangue já miscigenadamente brasileiro. Aprendendo a falar numa língua neolatina já abrasilei- 
rada, tropicalizada , africanizada, americanizada. Ouvindo cantar, chorar, rezar nessa língua. Vindo a ouvir nela diminutivos, aumentativos, palavrões. E vendo talvez mais do que outros meninos certos verdes, azuis, amarelos, vermelhos, roxos, alaranjados tropicalmente brasileiros. Andando descalço por massafês, por outros barros, por areias de praia, por capinzais. Distinguindo cajueiros de mangueiras, jenipapeiros de jaqueiras, urtigas de folhas de canela. Águas de rio, de águas de mar, cheiros de curral de cheiros de mel de açúcar a ferver em todos os engenhos antigos. Gostos de doces de gostos azedos da mesma cana. Rostos, sorrisos, cheiros, gestos de gentes brancas senhoris dos de gentes de cor e servis. E desde pequeno, me habituando a misturar o que distinguia. A criar predileções por misturas de paladar, de cheiros, de cores de gentes. (Freyre, 1980, p. 127)

A riqueza e a diversidade da obra de Gilberto Freyre se confirmam a cada nova leitura; o percurso descrito é sempre uma permanente surpresa, na medida em que, ao convidar o leitor a participar da reflexão desenvolvida, o transforma em ativo interlocutor.

Nesse sentido, torna-se oportuno registrar as sugestões de José Guilherme Merquior e Benedito Nunes, que propõem aproximar Gilberto Freyre e Oswald de Andrade, pelo fato de ambos se utilizarem das noções de anarquia e paradoxo. Esses dois autores teriam ressaltado o profundo rendimento interpretativo dessas noções, com vista à compreensão da cultura brasileira.

\section{A narrativa modernista: o ritmo do tempo}

Conforme já mencionado, o movimento modernista imprimiu em seus participantes um sentido de vanguarda, uma espécie de "alma antenada", o que, por outro lado, parece incidir sobre uma aguda percepção do tempo.

Essa percepção, por sua vez, permite a emergência de idéias correlatas como memória, tradição e história, pertencentes a um mesmo campo semântico, formando o que Foucault (1992) denominou de série discursiva.

Não é por outra razão que se constata na obra de Freyre inúmeras referências a Proust, momentos em que o autor dialoga com aquele, demarcando suas posições frente ao tempo, ao passado e à memória, 
como por exemplo no primeiro prefácio de Casa-Grande e Senzala (1933), no prefácio à edição do mesmo livro (1959), em vários artigos do livro Como e por que sou e não sou sociólogo (1968).

Ao pensar em Gilberto Freyre e no modernismo, optou-se por abordar como eixo básico as concepções de história e tradição. Mas aí surgiram novas indagações: que tratamento dar às categorias tempo e memória? Por que a insistência de Freyre em dialogar com Proust?

Uma primeira interpretação sugere que os dois autores poderiam ser considerados homólogos, uma vez que, para Proust, o tempo é feito de memória e, para Gilberto Freyre, a memória é feita de tempo ${ }^{2}$.

Ou seja, diferentemente de Proust que aponta para um tempo interior e, para quem a vivência do tempo só é possível através da memória - de um mergulho profundo no passado. Já para Gilberto Freyre, a memória é feita de um tempo dinâmico, de um tempo vivido que se faz presente - ultrapassando esse próprio presente e criando futuros possíveis.

E mais: para Gilberto Freyre, a memória só é possível através do tempo, pois, o tempo é feito de processos instantâneos e singulares que podem sempre descortinar substâncias várias, fluxos contínuos e descontínuos.

Memória é, nesse sentido, o tempo que se faz história. Este parece ser um dos traços mais modernistas de Gilberto Freyre, que compreende o sentido da história como um tempo que transcorre e faz girar múltiplos processos sociais, nutrindo de mudanças o tecido da vida.

Em Proust temos um tempo psicológico, em Freyre destaca-se um tempo raciológico.

As interpretações modernistas sobre a realidade brasileira fazem com que todos modifiquem o conceito de história até então reinante no pensamento social brasileiro, na medida em que este implicava uma concepção geográfica e biológica de história. Ou seja, os caracteres geográficos e biológicos seriam responsáveis pelas marcas históricas.

Os modernistas, ao contrário, passam a pensar a história como um processo sociocultural, que desenvolve mecanismos de adaptação dentro de um contexto étnico-ambiental. Dessa forma, deslocam o conceito de história da geografia e o conceito de cultura da raça. 
É por essa mesma razão que os chamados "explicadores do Brasil", Gilberto Freyre, com Casa-Grande e Senzala, Sérgio Buarque de Holanda, com Raízes do Brasil, e Caio Prado Júnior, com Formação do Brasil Contemporâneo, voltam-se ao período colonial e buscam reconstituir e analisar o processo histórico através do qual se constituiu a sociedade brasileira. Todos buscavam uma interpretação contem-porânea da sociedade, utilizando o que se convencionou chamar de argumento colonial: os modernistas voltaram-se ao estudo do passado, sem serem passadistas, traço que singulariza o movimento moder-nista brasileiro.

Dito de outra forma: voltavam-se ao passado como um mergulho, para vislumbrar outros presentes, novos futuros. Percebiam o tempo muito mais como intensidade, irradiação, e não, como linha cronológica a desdobrar-se teleologicamente. Estudar o passado significava torná-lo vivo.

Segundo Gilberto Freyre (1959, p. XXXIII):

Sem empatia, não é possível o estudo do passado assim amplo e intenso a um tempo, social e pessoal. Estudo que nos transmita do passado humano um pouco do que nele foi valor vivo, símbolo vivido; ou existência, vivência, experiência, condicionada por valores e símbolos.

Antônio Carlos Villaça, em estudo sobre Gilberto Freyre, assim se refere ao seu trabalho:

O fim da sua atividade criadora, notou-o muito bem Diogo de Melo Menezes, é o ressuscitar de passados perdidos, revelar vida, compreender pessoas, ser fiel à realidade no esforço de revelação, ressurreição, compreensão da vida humana no Brasil.

De modo geral, é comum encontrar entre os modernistas o sentido de revelação, quando em contato com o passado colonial brasileiro, em especial, com a arte barroca. Este sentimento aparece em Mário de Andrade nos artigos que escreveu sobre o Aleijadinho e nas Cartas de Trabalho sobre as suas pesquisas em torno do patrimônio, aparecendo, também, em inúmeros depoimentos de Lúcio Costa, Oscar Niemeyer e Carlos Drummond de Andrade, entre outros. 
Sabe-se que Gilberto Freyre escreveu Casa-Grande e Senzala não só como ensaio histórico-sociológico, mas também para reencontrar suas mais íntimas memórias.

Quando da publicação inaugural de Casa-Grande e Senzala, em seu primeiro prefácio, assim se expressou o autor:

A história social da Casa-Grande é a história íntima de quase todo brasileiro: de sua vida doméstica, conjugal, sob o patriarcalismo escravocrata e polígamo; da sua vida de menino; do seu cristianismo reduzido à religião de família e influenciado pelas crendices da senzala. $\mathrm{O}$ estudo da história íntima de um povo que tem alguma coisa de introspecção proustiana; os Goncort já o chamavam "a roman vrai". O arquiteto Lúcio Costa diante das casas velhas de Sabará, São João Del Rei, Ouro Preto, Mariana, das velhas casas grandes de Minas, foi a impressão que teve: “A gente como que se encontra... E se lembra de coisas que a gente nunca soube, mas que estavam lá dentro de nós. Não sei - Proust devia explicar isto direito. (Freyre, 1933)

Ricardo Benzaquem de Araújo (1994), interpretou Casa-Grande e Senzala como uma "casa em miniatura", onde se reconhece vida, onde a tradição transparece, imprimindo não só iluminação ao passado, mas também ao presente.

Os modernistas buscavam compreender a tradição em sua contemporaneidade. Uma tradição capaz de agir sobre si mesma ao incorporar mudanças, sem perder a pregnância do presente e, assim, alçando-se a novos futuros.

Gilberto Freyre, nos vários momentos em que busca um diálogo com Proust, argumenta que o tempo do passado contém fecundos e inesperados tempos contemporâneos. Há uma permanente e intrínseca relação entre o tempo do passado e do presente seguindo Gilberto Freyre:

O diálogo entre "tempo morto" e "tempo vivo" é, com efeito, uma das constantes filosóficas do livro Casa-Grande e Senzala constituindo uma expressão moderna de diálogo platônico sob aspecto dialético hegeliano. Tende esse diálogo a uma síntese daqueles dois tempos num terceiro, nem inteiramente morto, nem inteiramente vivo, dentro do qual viveria todo grupo humano cuja específica situação no espaço-tempo fosse identificada por uma análise de sua formação, ao mesmo tempo que de sua ecologia, 
semelhante à análise tentada, com audaciosa amplitude no espaço e, ao mesmo tempo, com ousada busca, é claro que não atingida, de profundidade no tempo, em Casa-Grande e Senzala.

Há muitas outras passagens onde Gilberto Freyre refere-se a Proust e, quase que invariavelmente, aproveita a oportunidade para rejeitar qualquer possibilidade nostálgica ou saudosista que buscasse reviver o passado tal qual ele foi. Desse modo, Freyre alinha-se com as propostas do subgrupo modernista, vinculado à Academia SPHAN, que pretende a valorização do passado, mas não se considera passadista, nem tampouco neocolonial, mas sim moderno.

Um outro longo texto de Gilberto Freyre é definitivamente esclarecedor de suas concepções sobre passado, memória e tempo:

Não me sinto inclinado a me deter na crítica, a meu ver de todo leviana, de ser Casa-Grande e Senzala livro saudosista: saudade do autor do tipo de vida vivido nas casas - grandes servidas pela senzala. (...) uma coisa é ser um autor saudosista em sua atitude decisiva com relação ao passado; outra coisa é servir-se o mesmo autor da saudade, ou, especificamente, da remembrança proustiana, como método empático de recapturar um tempo morto, procurando fazê-lo viver para que, ressuscitado possa esse passado ser como que apalpado pelos dedos dos São Tomés. Apalpado nas suas feridas e apalpados nas suas partes porventura sãs. Articulada com o presente e com o próprio futuro de uma sociedade ou de um tipo de sociedade a ponto de, sobre essa articulação, tentar-se uma interpretação sociológica, e não apenas histórica, de sociedades de um tipo que se caracteriza como patriarcal no seu conjunto de interelações e não apenas na sua organização de família. (1980, p. 161)

Freyre vive e recupera o tempo do passado através de um procedimento metódico, onde procura desdobrar pouco a pouco suas camadas de sentido, afastando-se, assim, de uma atitude contemplativa. Distintamente de Proust, não necessita dissolver sua consciência, ou melhor, as experiências mundanas pertinentes à forma e à substância, de modo a deixá-las livres, flutuando nas profundezas da mente, até que venham a adquirir seu significado. Freyre revela a significação plena das experiências do passado, relevando sua densidade histórica e mostrando como a memória está inscrita no tecido vivo do tempo. 
A compreensão do tempo interrelacionada com o modo específico de compreender a memória, a tradição e a história, faz com que Gilberto Freyre observe os fatos sociais como quem acaricia e apalpa idéias e dados empíricos, o que, igualmente, o conduz a ser sensível ao ritmo social, mais do que à simples história cronológica.

No artigo Como e porque escrevi Casa-Grande e Senzala, Gilberto Freyre esclarece mais uma vez sua proposta de construir uma totalidade sócio-histórica, para ordenar a experiência brasileira do período colonial. Experiência que possui um tempo que se desdobra e um ritmo que se dobra sobre sua própria sonoridade e silêncio.

Ainda sobre Casa-Grande e Senzala o autor afirma:

É certo, desse livro que se desenvolve sobre um lastro de fatos retirados principalmente do cotidiano da experiência brasileira durante os séculos mais profundamente patriarcais de formação na América Portuguesa de uma sociedade estável. Fatos, quase todos eles, recorrentes durante considerável período de tempo antes considerado no seu ritmo social do que na sua sequiência histórica. (Freyre, 1968, p. 119)

A noção de tempo é um dos patamares básicos na arquitetura do pensamento de Gilberto Freyre. Valoriza não o tempo cronológico, mas o tempo vivido da experiência. É o próprio autor que afirma:

A minha concepção de tempo como dinâmica social mais propriamente do que um fenômeno cronologicamente convencional, levará o leitor a encontrar numerosas referências a períodos passados, bem como a projeção em tempos mais contemporâneos. (Freyre, 1980, p. 34)

O tempo para Gilberto Freyre é o tempo vivido, tempo estendido do ócio, das festas, dos nascimentos e das mortes - tempo lento dos rituais.

A narrativa de Freyre, especialmente em Casa-Grande e Senzala, possui ritmo e vibração. É plena de sentidos, pois trata-se de um autor sensível ao ruído e ao cheiro, à forma e à cor, ao amor e ao ódio, ao riso e ao choro, sobretudo a ecos e premonições. Constata-se uma captura da linguagem em seu espaço de vivência - tempo vivido onde o concreto ressalta com todos os seus paradoxos a superfície do vivido. Revela-se uma captura através da linguagem, da experiência 
derretida do passado, onde sobressaem-se realidades vividas, interiorizadas - experiências encarnadas na concretude da história.

Segundo Julian Marias, Gilberto Freyre encontrou o que é mais próprio do hispânico, em uma dimensão mais profunda, estrategicamente antropológica - o sentido do tempo. Conforme o mesmo autor, "essa realidade (do homem como ser vivente) é intrinsecamente temporal, porém de tempo vivente, não do tempo 'estendidó - o tempo especializado do relógio. Para Gilberto Freyre (1980), este é o tempo hispânico, a maneira original de entender o tempo que tiveram durante séculos os povos de raiz portuguesa ou espanhola.

Richard Morse, em Espelho de Próspero (1988), chama de “Grande Desígnio Ocidental ” a linha de desenvolvimento que redunda nas modernas democracias européias e anglo-saxãs, mas também dá sua alternativa ibérica, derivada de um outro ocidente, mais escolástico e barroco, inspirado pela hierarquia, pela tradição e pela decidida busca de um ideal de comunidade.

Pode-se afirmar que a noção de tempo em Gilberto Freyre está ligada à noção de espaço, tendo, pois, um caráter visivelmente corpóreo, o que transforma o intérprete do Brasil num escritor sensível ao cheiro das pessoas, das ruas, das casas e de suas culinárias, enfim, sensível à arquitetura e ao modo de ser das cidades.

Portanto, nada mais modernista do que as concepções de tempo elaboradas por Gilberto Freyre. Aliás, no cerne do pensamento modernista, surge uma espécie de teoria da temporalidade brasileira, onde alguns intelectuais voltam-se ao estudo do passado para encontrar, em sua força geradora, um salto para o futuro.

A percepção de tempo como intensidade, como irradiação, e paralelamente ao mesmo tempo, como um instante fugidio, leva a consciência moderna a acentuar a aguda finitude da vida e a elaborar uma nova concepção de história.

História passa a ser não mais a descrição da fauna e da flora uma história natural -, nem tampouco uma história de corte positivista que supõe leis gerais e teológicas. A concepção de história então construída enfatiza os processos sociais, as práticas culturais, as representações simbólicas e, principalmente, as mudanças sociais.

O interesse de Gilberto Freyre está voltado para o cotidiano, para o dia-a-dia, para as experiências valorativas, isto é, experiências que 
na sociedade brasileira "se caracterizam como valores rurais, telúricos e agrários" (Freyre, 1933).

Gilberto Freyre, numa atitude extremamente moderna, mostrando estar atento ao seu tempo, aproxima-se da Escola dos Annales, onde Marc Bloch, Ferdinand Braudel e especialmente Lucien Febvre haviam formulado uma nova concepção de história, diametralmente oposta ao enfoque positivista. Esse grupo situa a origem da força integradora da história na estrutura básica de crenças, atividades, convicções ou aspirações, que dão a uma determinada sociedade ou período histórico um caráter específico e um significado inerente.

Gilberto Freyre já foi chamado por outros comentaristas de verdadeiro viajante no tempo e no espaço. Segundo Zevedei Barbu (1980, p. 64), sociólogo romeno, "só um historiador e poeta, percebe e forja o todo, o mais completo cosmos de significados e, a um só tempo, a totalidade mais concreta, incluindo-se o passado, o presente e o futuro, o real e o potencial, o imanente e o transcedente da vida humana nos trópicos, da qual a vida brasileira é uma modalidade".

Freyre construiu uma noção de história como totalidade que supõe e contém transformações no tempo. É nesse sentido que o estudo do complexo Casa-Grande e Senzala implicou volta ao passado, utilizando-se do argumento histórico da colonização para acompanhar as transformações rumo a novos futuros.

Surge, assim, um conceito renovado e ampliado de história, que dirige sua atenção tanto para a mudança na continuidade quanto para a continuidade na mudança. Tais processos devem ser captados em processos intersubjetivos, imersos nas práticas cotidianas e, como exemplo, pode-se citar as três modalidades de patriarcalismo que Freyre examinou: uma primeira, existente na ordem colonial rural e escravocrata; uma segunda, reinante numa sociedade já urbana e, finalmente, uma terceira, onde a família patriarcal vive sob as ordens de uma sociedade urbana e industrial.

Um dos traços modernistas mais marcantes em Gilberto Freyre e que permite aproximá-lo tanto de Mário de Andrade quanto de Sérgio Buarque de Holanda é, como já se disse, a profunda renovação que promove nos conceitos de memória, tempo e história, o que repercutirá diretamente sobre o modo de compreensão da categoria tradição. 
É dessa maneira que a modernidade marca o pensamento desses autores que, à semelhança de Walter Benjamin (1986), se recusam em pensar a história informada por um tempo homogêneo e unilinear. Para eles, contrariamente, o tempo é repleto de processos históricos irradiadores - daí a observação da história em seus momentos de intensidade. Talvez também derive daí a importância atribuída por Freyre aos processos de acomodação, de misturas existentes no período colonial brasileiro.

Esta reflexão nos remete a uma questão extremamente cara aos modernistas: como compreender a tradição? Ao contrário de outros movimentos de vanguarda europeus, como, por exemplo, o futurismo de Marinetti, que recusam valorizar qualquer tipo de tradição, o modernismo brasileiro reformula tal conceito. Busca uma tradição viva, não uma "tradição tumular", no dizer de Carlos Drummond de Andrade (A Revista, 1925), mas uma tradição capaz de emergir em fulgu-rações renovadas do presente.

No Brasil, além da renovação no conceito de tradição, este vem associado à idéia de misturas, o que confere às tradições culturais brasileiras vivacidade inaudita.

Segundo Benzaquem, "a proposta modernista - se é que se pode buscar um denominador comum num horizonte tão heterogêneo - elabora respostas interpretativas que puseram a questão cultural no centro, numa interessante simbiose sincrética do especificamente brasileiro com a herança e a criatividade contemporânea de toda humanidade".

Gilberto Freyre "vai apresentar uma concepção da vida social em condições de admitir, plasticamente, a influência de qualquer tradição, muçulmana, negra, judaica ou francesa, ampliando e alterando, no mesmo movimento, a própria noção de cultura", conforme análise do mesmo autor (Benzaquem, 1994, p. 103).

Da mistura das culturas que se encontraram nos trópicos americanos, surgiu a tradição brasileira que, em consonância com a estrutura socioeconômica, definiu a sociedade brasileira. A tradição parece ser um conceito chave para se comprender a trilogia escrita por Gilberto Freyre: Casa-Grande e Senzala (1933), Sobrados e Mocambos (1936) e Ordem e Progresso (1959).

Nesta trilogia transparece a análise de alguns fenômenos da cultura brasileira como o patriarcalismo, o tom verborrágico e retórico da 
intelligentsia e as festas sagradas e profanas - complexos culturais que exibem uma espécie de tradição progressiva, uma forma de continuidade através da mudança.

A idéia de tradição progressiva, conforme já aludimos, encontrase presente ao longo da trilogia mencionada, oportunidade em que Gilberto Freyre construiu um modelo de base histórica para compreender o padrão de relacionamento entre as tradições culturais.

Destacam-se em suas análises múltiplos núcleos temáticos: a realidade da casa, da família e da personalidade, entre outros. Todos eles atravessam transformações no tempo, mas mantém irredutível sua significação simbólica na dinâmica cultural brasileira.

Gilberto Freyre atribui especial ênfase ao conceito de personalidade, principalmente em função de sua capacidade de transformarse via reflexão e conhecimento. Essa concepção aproxima Gilberto Freyre de algumas análises clássicas sobre o tema feitas por Goethe, Max Weber, Nobert Elias e Thomas Mann, para citar os principais. Entre estas, destacam-se em particular as de Max Weber, que enfatiza ser o conceito de personalidade, como capacidade de mudar o mundo, um dos valores da modernidade. Aliás, modalidade essa assumida pelos primeiros protestantes e burgueses.

Além disso, Gilberto Freyre, como sujeito do conhecimento, assume uma personalidade que se desdobra em múltiplos personagens, conforme suas próprias palavras: "eu me desdobro, no menino, no negro, na mulher, no homem, no efeminado" (Freyre, 1980, p.117).

A personalidade de pesquisador adquire uma postura perspectivista, que lhe permite observar as mudanças de seus personagens em múltiplas experiências no tempo e no espaço. Por exemplo, a personalidade do senhor de engenho apresenta-se mais alargada e vulnerável no Brasil-Colônia e torna-se mais contida no Brasil-Império. Acompanhando essa mudança, também ocorrem modificações na personalidade do filho e da mulher, os quais, de completamente submissos, vão adquirindo autonomia ao longo do tempo.

Ainda a este respeito, ao comentar sobre as escolhas feitas para elaborar Casa-Grande e Senzala, o autor afirma que, em primeiro lugar, buscou assumir um ponto de vista móvel:

Ora, o assunto não era - nem é puramente europeu mas, em grande parte, extra-europeu. Não se defronta o autor com asperezas desse 
mesmo assunto nem como um sub-europeu passivamente colonial mas como um analista ou um intérprete do homem social, desdobrado - repita-se como autor em várias personalidades, que, nesses desdobramentos, precisava de identificar-se com elementos humanos e culturais além de não-europeus e de não-eruditos, folclóricos, vulgares, plebeus, contando que telúricos, da realidade brasileira. (Freyre, 1968, p.123)

Freyre faz menções, também, às mudanças que ocorrem no âmbito da família; para ele, a verdadeira unidade colonizadora da América portuguesa. Evidencia, por exemplo, que o modelo organizacional de base patriarcal sofre um conjunto de inflexões e modificações ao longo da história da sociedade brasileira.

No regime patriarcal do período colonial, caracterizado pela paisagem rural, pela autarquia do complexo socioeconômico casa-grande e senzala, o senhor de engenho desfruta de plenos poderes, o que, paradoxalmente, confere maleabilidade e capacidade de absorção do outro, mesmo que em posição subalterna. O patriarcalismo colonial, primeiro, se construiu sob o regime do hibridismo, absorvendo a multiplicidade cultural, mais do que apartando-a, sobretudo a relação da casa-grande com a senzala.

No decorrer do século XIX, sob o regime Imperial, surgem os sobrados e mocambos, um patriarcalismo mais austero, embora a autoridade do senhor já não reine mais absoluta. O filho, já bacharel, possui também alguma forma de poder na sociedade, o que começa a acarretar mudanças internas nas relações de autoridade entre os membros da família.

O patriarcalismo, na passagem da Monarquia para a República quando a sociedade começa a experimentar o processo de industrialização e enfatiza os mecanismos de urbanização -, assume novas feições: as relações interpessoais tornam-se mais atomizadas e as hierarquias mais rígidas, muito embora as práticas culturais das diferentes etnias continuem mantendo a capacidade de troca.

O marco cronológico que orienta Ordem e Progresso contempla o período que se estende de meados do século XIX (Lei do Ventre Livre) até o final da segunda década do século XX (início da Presidência Epitácio Pessoa). O objetivo era trabalhar com quatro gerações - bisavós, avós, pais e filhos - "um tempo sociologicamente único" (OP, p. XXI). Freyre procurou articular o passado social e cultural dos 
entrevistados com o seu presente e, em alguns momentos, com o seu próprio futuro, criando, assim, uma interdependência entre esses três tempos. Na sua concepção, é impossível separar, sociologicamente, o passado do presente, na medida em que o tempo "é psicológica e socialmente composto de variáveis que se alteram conforme o ritmo em que os vivem [...] diferentes subgrupos" (OP, p. XXXIX).

Assim, Gilberto Freyre vai observando a progressiva mudança e continuidade das diferentes tradições culturais brasileiras ao vinculálas à análise bastante crítica e lúcida do processo civilizador da sociedade brasileira e sua definitiva inclusão na modernidade ocidental.

A análise de Benzaquem sobre a obra de Gilberto Freyre esclarece como a "estrutura", a constituição interna do patriarcalismo, sofre modificações ao longo do tempo.

Segundo ele, "a partir de uma série de modificações na economia - com o fortalecimento do comércio, das cidades e a crescente diminuição da escravidão; na política - com a transferência da soberania dos senhores de engenho para o Estado Imperial e o natural abrandamento daquela atmosfera de anarquia "feudal" que predominava até então; e na cultura - com o avanço de um processo civilizador no País, o caráter do patriarcalismo estudado em Casa-Grande e Senzala havia sofrido uma profunda modificação. Destituído, agora, de suas funções públicas, ele perde também a oportunidade de criar um ambiente doméstico que, mesmo farto de exageros de natureza sexual, não deixava de estimular, sem prejuízo do despotismo inerente ao regime escravocrata, uma relativa e precária intimidade entre senhores e escravos".

Vejamos o que diz a esse respeito o próprio Gilberto Freyre (1933, p.160):

O sistema casa-grande - senzala se partira quase pelo meio, os elementos soltos espalhando-se um pouco por toda a parte e completando-se mal nos seus antagonismos de cultura européia e de cultura africana ou indígena. Antagonismos outrora mantidos em equilíbrio à sombra dos engenhos.

Gilberto Freyre, ao estudar o patriarcalismo brasileiro, perguntase como é possível manter a tradição dos antagonismos em equilíbrio, tão característico da sociedade híbrida do período colonial. 
E ele mesmo responde, com certa indignação, que o hibridismo frenético da fase colonial transforma-se em dualismos no decorrer do século XIX, tais como moços e velhos; homem e mulher; urbano e rural; cosmopolitismo e ruralismo.

Outra dimensão da realidade que Gilberto Freyre observa, diz respeito à presença de uma tradição progressiva referente à continuidade do estilo de educação implantado no Brasil. Há uma continuidade entre a educação jesuítica até o século XVIII e a formação do bacharel do século XIX. Em ambas as situações permanece o abuso da retórica, o tom eloqüente e verborrágico. Valeria perguntar: como se mantém essa tradição atualmente entre nós?

Outro modo de compreender a tradição presente no pensamento de Gilberto Freyre, e profundamente em sintonia com as propostas modernistas, diz respeito ao elogio das misturas, ao entrelaçamento das tradições. Este processo resultou na construção de uma nacionalidade, que se afastando de qualquer consideração sobre uma substância antológica, focaliza "uma maneira particular, híbrida e plástica de combinar as mais diferentes tradições sem pretender fundilas em uma síntese completa e definitiva: antagonismos em equilíbrio" (Benzaquem, 1994, p.135).

A narrativa do autor possui um tom frenético, que acentua seu ritmo pleno de imagens:

Nem intransigentemente de uma nem de outra (i. e, Europa e África), mas das duas. A influência africana fervendo sob a européia e dando um acre requeime à vida sexual, à alimentação, à religião; o sangue mouro ou negro correndo por uma grande população brancarona quando não predominando em regiões ainda hoje de gente escura; o ar da África, um ar quente, oleoso, amolecendo nas instituições e nas formas de cultura as durezas germânicas, corrompendo a rigidez moral e doutrinária da Igreja medieval; tirando os ossos ao Cristianismo, feudalismo, à arquitetura gótica, à disciplina canônica, ao direito visigótico, ao latim, ao próprio caráter do povo, A Europa reinando mas sem governar; governando antes a África. (Freyre, 1933, p.5)

O que Gilberto Freyre mais valoriza no colonizador é justamente sua capacidade de misturar-se, sua miscibilidade, o que garantiu sempre uma enorme plasticidade à cultura portuguesa, fazendo com que esta 
tanto imprimisse suas marcas em outras culturas que manteve contato tanto quanto recebesse influências daquelas.

No artigo "Sugestões para o estudo da arte brasileira em relações com a de Portugal e das colônias", publicado na Revista do SPHAN, o autor faz o seguinte comentário sobre a cultura da gente de Portugal:

Um povo com uma capacidade única de perpetuar-se em outros povos. Dissolvendo-se neles a ponto de parecer ir perder-se nos sangues e nas culturas estranhas mas ao mesmo tempo comunicando-lhes tantos de seus motivos essenciais de vida e tantas das suas maneiras mais profundas de ser que, passados séculos, os traços portugueses se conservam nos traços dos homens e na fisionomia das casas, dos móveis, dos jardins, das embarcações, das formas de bolo. (Freyre, 1933, p.173)

Demonstrando altivez e grande capacidade de observação, atitude extremamente constante em muitos modernistas, como Oswald de Andrade e Mario de Andrade, entre outros, Freyre reverte por completo o complexo de inferioridade frente às culturas européias:

Por outro lado, não deixou de haver sobre a arte culta e popular de Portugal, brasileira, e não só sugestão da natureza em seu estado cru como influência de uma paisagem e de um meio social coloridos fortemente pela escravidão e pela miscigenação. Esses traços de influência ou de sugestão brasileira sobre a arte portuguesa da Europa estão exigindo uma análise pachorrenta e demorada. (Modernistas na repartição. 1993, p.172)

A observação da mistura de tradições, leva Gilberto Freyre a enfatizar que a singularidade da sociedade brasileira consiste na experiência da permeabilidade entre as tradições culturais aqui existentes.

A respeito dessa questão, Freyre retoma suas reflexões sobre o ser hispânico, cujas características mais marcantes, segundo ele, seriam o seu pluralismo de comportamento, entre outros motivos, pelo fato de a Península situar-se no entre-lugar de duas civilizações: a européia e a árabe-oriental.

Ao analisar-se a trilogia composta por Freyre, especialmente Casa-Grande e Senzala e Sobrados e Mocambos, a constituição de uma tradição brasileira, suas transformações e modulações através 
do tempo histórico, revela-se como um dos eixos fundamentais de sua argumentação.

Revela-se, igualmente, uma admiração inequívoca do período colonial, de onde se teria gestado a matriz da cultura brasileira, plena de hibridismo, de misturas, de fluxos simbólicos variados e múltiplos artifícios, como a inclusão do pecado nas considerações religiosas.

Gilberto Freyre interpreta a sociedade dos séculos XVI e XVII, sob o signo do excesso. Mas, ao mesmo tempo, aponta para o processo social onde as diferenças culturais são continuamente submetidas a um processo de equilíbrio e aproximação.

No entanto, o excesso é uma espécie de mecanismo fundante da intersubjetividade necessária à construção da sociedade. Excesso sexual, de ócio, de magia, de violência e de sadomasoquismo. Numa das melhores definições sobre a cultura brasileira, Freyre a interpreta pelo excesso de mestiçagem, o que significa, no seu próprio vocabulário, diferença, hibridismo, ambigüidade e indefinição.

O patriarcalismo, em sua modalidade brasileira, apresentou todo tipo de excesso. A hybris foi vivenciada até o limite da morte, processo que Gilberto Freyre evidencia por intermédio da disseminação da sífilis naqueles tempos. Segundo ele, excesso de emoção e furor.

O português-colonizador aparece em Casa-Grande e Senzala como um personagem híbrido; a cultura negra aparece com expressiva vocação mediadora entre a cultura portuguesa e a cultura indígena.

Neste livro paradigmático sobre a cultura brasileira, descortinamse, em suma, a percepção e a formação de uma imagem extremamente híbrida, sincrética e polifônica da sociedade brasileira.

Por fim, é o conceito de tradição, tal como trabalhado por Gilberto Freyre (e segundo nossa hipótese, por todo um subgrupo modernista, especialmente aquele vinculado à "Academia SPHAN"), que possibilitou-lhe uma ampliação da análise sobre os processos constitutivos da cultura brasileira. Tal postura permitiu-lhe, inclusive, realizar uma desnaturalização do escravo, ao demonstrar que esta é apenas uma condição social historicamente construída, que não deve camuflar a riqueza e a dinâmica da cultura africana. Nesse mesmo diapasão, encontra-se valorizada a existência de uma tradição popular estável, que passa da senzala aos mocambos, às favelas, mas que, a par de seu deslocamento no espaço, mantém certa consistência no 
tempo. É esta tradição que se constitui no tecido da história e se transforma no ritmo do tempo que Gilberto Freyre observa. É por essa mesma razão que o autor se volta à análise das práticas culturais cotidianas, aquelas que revelam a intimidade e a totalidade do ser como individuação e como sociabilidade (Simimel, 1992).

E nesse sentido, um traço profundamente modernista de Gilberto Freyre se ilumina: a presença de uma nova postura racional, subjetivamente instrumentalizável diante da realidade brasileira. Portanto, era preciso estudá-la, pesquisá-la, escutá-la, ir às fontes primárias, ouvir a voz das diversas etnias, apalpar de perto a história interna da cultura brasileira.

É Gilberto Freyre (1968) quem afirma: “ora, a grande história é a história social. É a história íntima, e da história íntima fazem parte as superstições, as ilusões, os mitos".

Há, portanto, em toda a obra de Gilberto Freyre uma pesquisa sistemática sobre os fatos que observa. Em verdade, os modernistas recusam o tom verborrágico, eloqüente e considerado vazio das gerações anteriores.

A análise do cotidiano requer procedimentos de pesquisa apurados e atenta análise, o que exige, ao mesmo tempo, a capacidade de transferir-se o particular significativo para o universal expressivo. Nesse aspecto, Freyre foi exemplar, conforme observou Roger Bastide em análise sobre a obra do autor.

Gilberto Freyre buscou, num gesto missionário tão característico do horizonte modernista, trazer a expressão plena, aquela experiência brasileira ainda muda em muitos aspectos; trata-se, pois, de trazer à superfície discursiva a expressão pura de um sentido próprio à história da cultura brasileira.

O autor promoveu a observação de elementos dionisíacos da cultura, capazes, também eles, de promover coesão social através do lúdico, do erótico, dos sentidos e da emoção estética, o que nos permite, contemporaneamente, aproximar o pensamento de Freyre das proposições desenvolvidas por dois outros sociólogos: George Simmel e Michel Maffesoli, as quais apresentam grande rendimento para estudar a cultura brasileira contemporânea.

A narrativa freyreana possui um ritmo intenso; a realidade brasileira parece falar com sotaque próprio. A discussão sobre uma língua 
brasileira, a mescla entre a cultura culta e a popular, a incorporação da história oral e das trajetórias de vida são procedimentos especialmente modernistas e que aparecem em Gilberto Freyre.

A isso ainda se pode agregar outro traço da riqueza metodológica do autor: a incorporação da diversidade dos grupos sociais contemplados pelas pesquisas realizadas, resultado direto da utilização do conceito de cultura, o que permite uma análise congregada, ampla e diversificada da realidade, ao contrário daquela que privilegia a noção de raça, que separa, diverge e hierarquiza.

Freyre utiliza a linguagem do cotidiano, a linguagem da praça pública, do corpo, do sexo, das festas sagradas e profanas. Nesse sentido, é possível também aproximar suas análises daquelas desenvolvidas por M. Bakhtin, em seu grandioso livro A Cultura Popular e o Renascimento Europeu.

O fato é que Gilberto Freyre explorou em profundidade o domínio da vivência concreta da família patriarcal - a verdadeira unidade colonizadora - e as diferentes formas de racionalidade existentes nos trópicos. É por esse motivo que sua narrativa apresenta um tom de vivacidade, capaz de transformar o leitor em interlocutor, permitindolhe momentos de interrogação e de diálogo, o que transforma a leitura de sua obra em construção de espaço de enunciação, onde a reflexão se amplia sobremaneira.

A obra de Gilberto Freyre descortina verdadeira experiência sobre a realidade brasileira, abrindo espaço para um intenso percurso pelos seus meandros internos. Entre outros aspectos, sua atitude perspectivista e seu conceito de personalidade como capacidade transformadora fazem com que seja possível o leitor "experienciar" o verdadeiro mergulho nas conexões internas e mais sutis da cultura.

Roberto da Matta, ao analisar a obra de Gilberto Freyre, faz o seguinte comentário sobre a complexidade e a riqueza do método de análise empregado pelo autor:

Essa relação difícil e complexa entre o intelectual e o sensível, o de dentro e o de fora, o vivido e o conceitualizado, o local e universal, o que requer tradução e aquilo que faz parte do ar que se respira que Gilberto Freyre quer estudar e, eventualmente equilibrar, em sua obra. 
É importante ressaltar a unidade de Gilberto Freyre na observação das transformações históricas. Conforme dito, a defesa da tradição impõe em Gilberto Freyre um dos mais marcantes traços de seu modernismo, que é a capacidade concomitante de observação dos avanços da modernidade.

Esta modernidade é observada por exemplo através da importância que Freyre atribui à urbanidade na nova estruturação das relações sociais na sociedade brasileira. Tais fatos são observados através da percepção do impacto das novas relações que ocorrem sob o espaço da cidade e fazem mudar o cenário dos valores e dos interesses, dominantes, no cenário da realidade brasileira.

Em Sobrados e Mocambos, o autor observa o século XIX e a sociedade brasileira em intenso processo de urbanização, o que faz aparecer uma nova aristocracia de sobrado, diversa da comercial. Aristocracia de "toga e de beca". É a presença dos bacharéis trazendo mudanças na cultura e na política do país.

A urbanidade, isto é, a disseminação de um estilo de vida urbano, se intensifica no Brasil nos anos 30, o que acelera os processos de inclusão do país na modernidade ocidental, promovendo um reordenamento sociohistórico no plano interno da cultura. É um momento de acelerada modernização e mudança dos padrões estéticos e dos modos de vida. Assiste-se do final do século XIX até as primeiras décadas do século XX uma profunda imitação da cultura francesa.

Esse processo não passa desapercebido para a sensibilidade modernista de Gilberto Freyre, nem tampouco para outros contemporâneos seus, que escreveram guias históricos, sentimentais e líricos sobre as cidades históricas, ou ainda, poemas memoráveis, como o que o próprio Gilberto Freyre escreveu sobre Recife e Olinda, ou aqueles escritos por Manuel Bandeira, sobre Recife, Olinda e Ouro Preto, ou Mário de Andrade sobre São Paulo, Belo Horizonte, etc.

$\mathrm{O}$ aumento da complexidade da vida urbana traz consigo a criação e diversificação de valores e interesses. A multiplicidade de valores é uma característica da modernidade, segundo Max Weber (Economia e Sociedade, 1990). Gilberto Freyre está atento não só à observação de tal multiplicidade, como à dinâmica da cultura exposta em suas múltiplas interconexões, dobras e desdobramentos no interior de uma totalidade histórica. 
Tal discussão nos conduz a um último ponto que merece atenção para esclarecer importante traço modernista na obra de Gilberto Freyre. Trata-se do uso sistemático de um método de análise sobre a realidade brasileira, cujo maior rendimento analítico consiste em construir uma visão alerquinal, em consonância com Mario de Andrade na construção de Macunaíma. Gilberto Freyre, com agudo senso analítico, igualmente ressalta, em seus diversos trabalhos, as permanentes e múltiplas interrelações existentes no interior da cultura, como, por exemplo, as transformações concomitantes entre a organização da vida privada familiar (dos diferentes tipos de patriarcalismos) e o formato do regime político das constituições, ou seja, evidencia a relação entre vida privada e a cultura política brasileira.

Conforme o autor:

a transição do patriarcalismo absoluto para o semipatriarcalismo (que) alguém já se lembrou de comparar com a transição da monarquia absoluta para a constitucional. (Freyre, 1933, p.130)

É preciso, porém, evidenciar que Gilberto Freyre não pretendia construir uma interpretação do Brasil que resultasse na idéia de soma ou síntese. A proposta deste intelectual consiste na construção de uma noção de totalidade histórica que mantém um sentido aberto às transformações sociais e às múltiplas possibilidades de metamorfoses simbólicas e arranjos interpretativos polissêmicos.

Em verdade, pode-se arriscar a idéia de que a interpretação modernista de Gilberto Freyre constrói não uma metáfora sobre a cultura brasileira, mas uma alegoria, isto é, uma totalidade aberta à múltiplos sentidos. 


\title{
Notas
}

1 Da pesquisa de campo citada, resultou tese de doutorado da autora do presente artigo, com o título - O Tecido do Tempo: a idéia de patrimônio cultural no Brasil, 1920-1970.

2 Esta é uma idéia que se encontra ainda em primeira versão, e aponta para questões complexas que devem ser aprofundadas. Fica como sugestão para reflexão e pesquisa.

3 Grupo de intelectuais e amigos que trabalhavam e se reuniam em torno da instituição Serviço do Patrimônio Histórico e Artístico Nacional.

\begin{abstract}
The article discusses Gilberto Freyre's position on the horizon of Brazilian modernism and builds its arguments upon the shared ideals of his generation. The main interpretative lines responsible for the renewal of Brazilian thoughts can be summarized by the replacement of the concept of Race by Culture, and by the alterations in the concepts of History, Memory, Time and Tradition.
\end{abstract}

Résumé. L'article entame une discussion sur l'insertion de Gilberto Freyre dans l’horizon du modernisme brésilien et bâtit son argument à partir des idéaux partagés avec les intellectuels de la même génération. Les idées les plus importantes, responsables pour le renouveau de la pensée sur le Brésil, peuvent être resumées par le remplacement du concept de Race par celui de Culture et par le déplacement des concepts d'Histoire, Mémoire, Temps et Tradition.

\section{Referências Bibliográficas}

Benzaquem, Araújo Ricardo (1994). Guerra e paz: casa-grande e senzala e a obra de Gilberto Freyre nos anos 30. Rio de Janeiro: Ed. 34 Letras.

Cavalcanti, Lauro (org.) (1993). Modernistas na repartição. Rio de Janeiro: Tempo Brasileiro. Ed. UFRJ/Paço Imperial.

Costa Lima, Luiz (1929). A aguarrás do tempo. Rio de Janeiro: Ed. Roceo. 
Freyre, Gilberto [1933] (1971). Casa-Grande e senzala. Rio de Janeiro: Aguilar.

(1936). Sobrados e mocambos. Rio de Janeiro: Ed. José Olympio.

(1959). Ordem e progresso. Rio de Janeiro: Ed. José Olympio.

(1975). O brasileiro entre outros hispanos: afinidades, contrastes e possíveis futuros nas suas interrelações. Rio de Janeiro: Ed. José Olympio.

(1968). Como e por que sou e não sou sociólogo. Brasília: Ed. Universidade de Brasília.

(1993). "Sugestões para o estudo da Arte brasileira em relação com a de Portugal e as das colônias". In: Modernistas na repartição. Organizada por Lauro Cavalcanti. Rio de Janeiro: Tempo Brasileiro, Editora UFRJ/Paço Imperial.

(1980). Gilberto Freyre na UnB.Coleção Itinerários. Brasília: Editora Universidade de Brasília.

IÑIguEZ, Carlos Piñeiro (1999). Sueños paralelos. Centro de Estudios de Politica Exterior en el Cari. Consejo Argentino para las Relaciones Internacionales. Buenos Aires: Ed. Nuevo hacer. Argentina.

Mendonça Teles, Gilberto (1992). Vanguarda européia e Modernismo brasileiro. Petrópolis: Vozes.

Rodrigues de FAria, Nina (1998). "Histórias de vida". Revista Sociedade e Estado, vol. XIII, n. ${ }^{\circ}$ 2, julho-dezembro. 